\title{
Penciptaan Keteng-Keteng Elektrik Telu Ngawan
}

\author{
Adina Sastra Sembiring, Uyuni Widiastuti, Brepin Tarigan \\ Program Studi Pendidikan Musik, Fakultas Bahasa dan Seni, \\ Universitas Negeri Medan \\ E-mail: adina_matheny@yahoo.com
}

\begin{abstract}
Keteng-keteng is a traditional Karo music that is played by beating with two sticks. So far, the keteng-keteng is made from one segment of bamboo, therefore this research creates an electric keteng-keteng telu ngawan which is the development of one bamboo segment into three bamboo sections by adding an equalizer to the keteng-keteng so that the sound of the keteng-keteng is actually can be adjusted according to the color of the sound on the middle bass and treble. The objectives of this study were to: (1) produce an electric keteng-keteng telu ngawan; (2) to know the electric keteng-keteng telu ngawan play technique; (3) to determine the musical composition of electric keteng-keteng telu ngawan. The method used in this research is the Research \& Development approach, which consists of: (1) defining the concept of creating an electric keteng-keteng telu ngawan; (2) Creation of an electric keteng-keteng telu ngawan; (3) validation by experts, namely the traditional Karo music artist. With the creation of the electric Telu Ngawan, it can minimize the keteng-keteng play and produce the electric keteng-keteng telu ngawan sound with three different characters, namely high, midle and low characters. From this combination, two different gung characters were found because beruna uses a vibrating aid while daluna does not use a vibrating aid.
\end{abstract}

Keywords: Creation, Keteng-Keteng, Electric, Telu Ngawan.

\begin{abstract}
Abstrak: Keteng-keteng merupakan salah satu musik tradisional Karo yang dimainkan dengan cara dipukul menggunakan dua buah stik. Selama ini keteng-keteng terbuat dari satu ruas bambu, oleh sebab itu maka penelitian ini menciptakan keteng-keteng elektrik telu ngawan yang merupakan pengembangan dari satu ruas bambu menjadi tiga ruas bambu dengan menambahkan equalizer kedalam keteng-keteng sehingga suara keteng-keteng yang dihasilkan benar-benar dapat diatur sesuai dengan warna suara pada bass middle dan treble. Tujuan penelitian ini adalah untuk: (1) untuk menghasilkan keteng-keteng elektrik telu ngawan; (2) untuk mengetahui teknik permainan keteng-keteng elektrik telu ngawan; (3) untuk mengetahui komposisi musik keteng-keteng elektrik telu ngawan. Metode yang digunakan pada penelitian ini adalah pendekatan Research \& Development, yang terdiri dari: (1) Mendefenisikan konsep penciptaan keteng-keteng elektrik telu ngawan; (2) Penciptaan keteng-keteng elektrik telu ngawan; (3) validasi oleh ahli yaitu seniman musik tradisional Karo. Dengan diciptakannya keteng-keteng elektrik telu ngawan, maka dapat meminimalisir permainan keteng-keteng dan menghasilkan suara Keteng- Keteng Elektrik Telu Ngawan dengan tiga karakter yang berbeda yaitu karakter high,midle dan low. Dari penggabungan ini maka ditemukan dua karakter gung yang berbeda karena beruna memakai alat bantu getar sedangkan daluna tidak memakai alat bantu getar.
\end{abstract}

Kata Kunci: Penciptaan, Keteng-Keteng, Elektrik, Telu Ngawan.

\section{PENDAHULUAN}

Keteng-keteng merupakan salah satu musik tradisional yang berasal dari daerah karo Sumatera Utara. Selama ini keteng-keteng yang ada hanya terbuat dari satu ruas bambu, sehingga bunyi yang dihasilkan tidak maksimal. Oleh sebab itu peneliti akan menciptakan keteng- keteng elektrik yang menggunakan tiga ruas bambu (Telu Ngawan). Keteng-keteng ini nantinya akan menggunakan elektronik equalizer, sehingga akan menjadi alat musik akustik elektrik. Suara yang dihasilkan oleh keteng-keteng elektrik Telu Ngawan nantinya dapat diatur sesuai dengan warna suara pada bass middle dan treble. Perubahan ketengketeng ini sangat penting di dalam pertunjukan musik tradisional karo karena dapat meminimalisir pemain keteng-keteng yang biasanya bisa sampai lima pemain, namun dengan adanya keteng-keteng elektrik Telu Ngawan hanya dimainkan oleh tiga pemain saja. Keteng-keteng yang digunakan juga lebih sedikit biasanya satu pemain dengan satu keteng-keteng, namun dengan adanya penciptaan baru maka keteng-keteng elektrik telu ngawan dimainkan oleh tiga pemain sesuai dengan teknik permainan pada keteng-keteng aslinya.

Dari paparan di atas peneliti tertarik untuk menciptakan keteng-keteng elektrik Telu Ngawan menjadi satu penelitian yang berjudul Penciptaan Keteng-keteng Elektrik Telu 
Ngawan, sehingga tujuan dari penelitian ini adalah: (1) untuk menghasilkan keteng-keteng elektrik telu ngawan; (2) untuk mengetahui teknik permainan keteng-keteng elektrik telu ngawan; (3) untuk mengetahui komposisi music keteng-keteng elektrik telu ngawan.

Organologi merupakan ilmu tentang struktur instrumen musik berdasarkan sumber bunyi, cara memproduksi bunyi dan sistem pelarasan. Menurut Kriswanto (2008) organologi berasal dari kata organ yang berarti benda, alat atau barang dan $\log i$ berarti ilmu. Jadi secara sederhana dapat diartikan bahwa organologi adalah ilmu yang mempelajari tentang benda atau alat. Organologi mempunyai maksud sebagai gambaran tentang bentuk dan rupa, konstruksi suatu alat musik. Organologi mempelajari tentang struktur musik berdasarkan sumber bunyi, cara memproduksi bunyi, dan sistem pelarasan. Organologi mrmpunyai maksud sebagai gambaran tentang bentuk dan rupa susunan pembangunan konstruksi sebuah alat musik sehingga dapat menghasilkan bunyi . Organologi dalam istilah musik merupakan ilmu alat musik, studi mengenai alat musik.

Alat musik merupakan suatu alat yang diciptakan untuk menghasilkan bunyi, hal ini sejalan dengan pendapat Sri Hendarto (2011) bahwa instrumen musik adalah sarana untuk penampilan suatu kesenian. Alat musik dapat dibedakan dari sumber bunyi dan cara memainkannya. Menurut sumber bunyinya pengelompokkan alat musik terdiri dari:

1. Chordhophone, alat musik yang sumber bunyinya dari tali senar atau dawai, seperti: gitar, biola, cello, harpa, alto, mandolin, banyo.

2. Aerophone, alat musik yang sumber bunyinya dari udara, yang dimainkan dengan ditiup, seperti: rekorder, pikolo, flute, trompet, trombone, tuna, clarinet, oboe, saxsophone.

3. Idiophone, alat musik yang sumber bunyinya dari batangan logam atau kayu yang berasal dari alat musik itu sendiri, seperti: kulintang, bel, angklung, maracas.

4. Membraphone, alat musik yang sumber bunyinya dari getaran pada selaput tipis yang terbuat dari kulit atau plastik seperti: gendang, gamelan, calung.

5. Electrophone, alat musik yang sumber bunyinya dibantu atau disebabkan adanya

daya listrik, seperti clavinova, orgen, keyboard, gitar elektrik, bas elektrik.

Musik tradisional merupakan kumpulan komposisi, struktur, idiom dan instrumentasi serta gaya maupun elemen yang tidak diambil dari sistem musikal yang berasal luar budaya suatu masyarakat yang dimaksud.Menurut Purba (2007) musik tradisional bersifat khas dan mencerminkan kebudayaan suatu etnis atau masyarakat. Penggunaan musik tradisional dalam upacara adat pada masyarakat suku karo diantaranya adalah upacara pernikahan, upacara kematian, upacara erpangir $k u$ lau (membersihkan diri), mengket rumah (masuk rumah baru), dan gendang guro-guro aron (pesta muda mudi).

Alat musik tradisional karo dapat diklasifiksikan menurut sumber bunyinya, seperti: Chordhophone ada pada alat musik kulcapi dan murbab, Aerophone ada pada alat musik surdan, sarune, balobat dan embelembel, Membraphone ada pada alat musik gendang singanaki, gendang singindungi, dan Idiophone ada pada alat musik keteng-keteng.

Keteng-Keteng memiliki panjang sekitar setengah meter dan memiliki senar yang terbuat dari potongan bambu dan terdiri dari dua buah. Panjang Keteng-Keteng $58 \mathrm{~cm}$, garis menengahnya kira-kira $12 \mathrm{~cm}$. Cara memainkan alat ini sangat sederhana seperti layaknya memukul alat musik drum. Dilihat dari segi fungsinya keteng-keteng sering dimainkan dalam musik gendang telu sendalanen sebagai media dalam upacara Erpangir Ku Lau oleh masyarakat Karo.

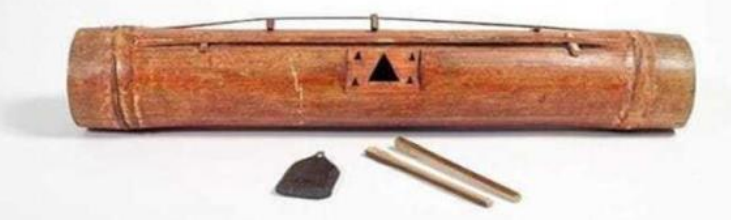

Gambar 1. Alat musik keteng-keteng

\section{METODE}

\section{Pendekatan Penelitian}

Penelitian ini menggunakan pendekatan Research \& Development, langkah-langkah yang dilakukan pada penelitian ini adalah: (1) Mendefenisikan konsep penciptaan keteng- 
keteng elektrik telu ngawan; (2) Penciptaan keteng-keteng elektrik telu ngawan; (3) hasil penciptaan keteng-keteng elektrik telu ngawan divalidasi oleh ahlinya yaitu seniman musik tradisional Karo.

\section{Sumber Data}

Sumber data pada penelitian ini menggunakan dat primer dan sekunder.Data Primer adalah data yang diperoleh secara langsung dari informan yaitu pembuat ketengketeng di Galeri Mejuah Juah Jalan Perumahan Salam Tani Blok E No. 40 Pancur Batu. Datadata primer diperoleh melalui teknik wawancara mendalam (depth interview) dan pengamatan berperan serta (participant observation. Data Sekunder adalah data yang diperoleh dari sumber lain, seperti: buku, rekaman, jurnal, atau dari sumber lainnya agar dapat menunjang data penelitian.

\section{Teknik Pengumpul Data}

Teknik pengumpul data pada penelitian ini adalah: (1) Observasi, dilakukan untuk mengkonfirmasi data yang telah terkumpul yang dilakukan dengan mengamati secara langsung; (2) Wawancara, digunakan untuk komunikasi dengan pihak terkait seperti pembuat keteng-keteng di galeri mejuah-juah; (3) Dokumentasi, dilakukan untu menunjang proses penelitian, dimana tidak semua hal dapat diketahui. Oleh sebab itu dapat dilakukan dengan mencatat, transkrip, buku, rekaman dan lain sebagainya

\section{Teknik Analisis Data}

Teknik analisis data dilakukan dengan mengkategorikan dan menganalisis data primer dan data sekunder melalui diskusi ahli. Selanjutnya merumuskan konsep dan model penciptaan keteng-keteng elektrik telu ngawan.

\section{HASIL DAN PEMBAHASAN}

Secara umum keteng-keteng memiliki dua jenis, yakni keteng-keteng dalu-dalu dan keteng-keteng beru-beru. Perbedaan ketengketeng dalu-dalu dan keteng-keteng beru-beru terlihat dari jumlah talinya. Keteng-keteng dalu-dalu memiliki tiga tali, sedangkan ketengketeng beru-beru memiliki dua tali serta memiliki lidah atau ampik-ampik.

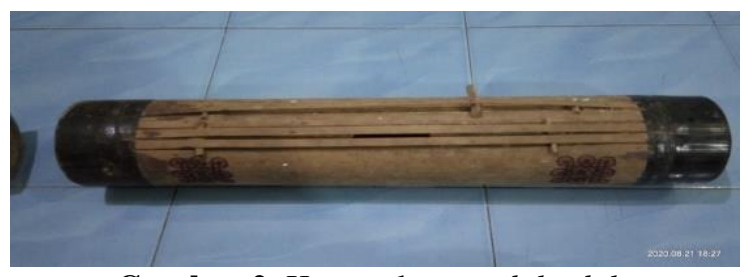

Gambar 2. Keteng-keteng dalu-dalu

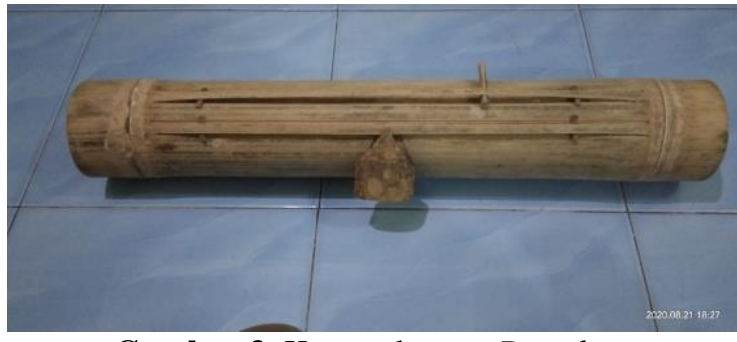

Gambar 3. Keteng-keteng Beru-beru

Penciptaan keteng-keteng elektrik telu ngawan dilakukan dengan cara meng-explore warna bunyi (timbre) dalam satu bambu yang memiliki tiga ruas. Ketiga ruas bambu dituning berbeda melalui senar dan lubang resonansi serta dilah atau lidah penggetar suara. Ketiga karakter yaitu high, midle, low akan ditentukan dari tebal tipisnya senar dan besar kecilnya lubang resonansi serta ukuran dilah-nya.

Proses Pembuatan Keteng Elektrik Telu Ngawan

Keteng Elektrik Telu Ngawan dapat menghasilkan bunyi keteng-keteng yang baik, oleh sebab itu harus memilih bambu besar (buluh belin), minimal berukuran $5 \mathrm{~cm}$ untuk diameternya dan $11 \mathrm{~cm}$ untuk panjang satu ruasnya. hal ini sesuai dengan penelitian Lucky Hermansyah (2020) yang mengatakan bahwa Pemilihan bahan merupakan hal yang penting dilakukan sebagai awal untuk mendapatkan bahan yang berkualitas.

Bambu yang sudah diukur panjang dan diameternya selanjutnya direndam selama kurang lebih satu minggu.Bambu untuk membuat keteng-keteng dibiarkan dalam air kurang lebih satu minggu agar suara dan ketahanan bambu menjadi lebih baik. Setelah satu minggu bambu yang sudah direndam kemudian dikeringkan kurang lebih satu minggu untuk menghilangkan sisa air yang masih tertinggal di dalam bambu. Selanjutnya, setelah kedua proses ini selesai, bambu mulai di alis untuk dijadikan keteng-keteng elektrik Telu Ngawan. Berikut beberapa foto pada proses penciptaan keteng-keteng elektrik telu ngawan.

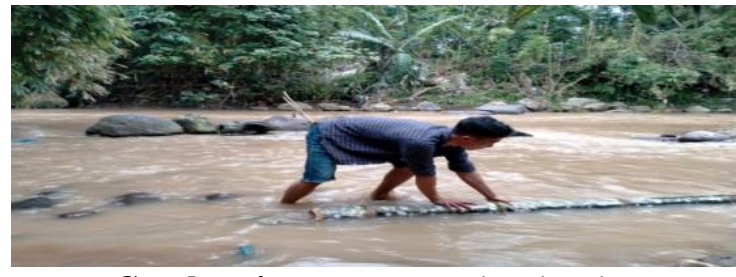

Gambar 4. Proses merendam bambu 


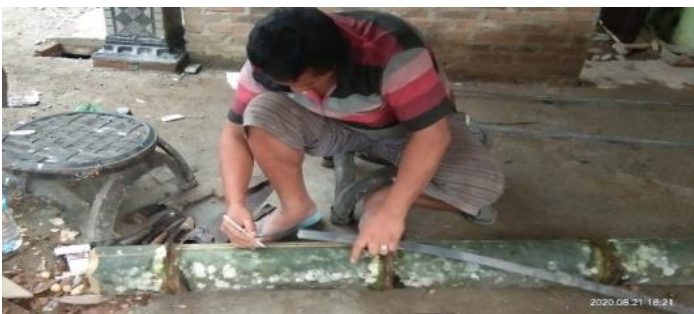

Gambar 5. Proses meng-alis senar keteng-keteng

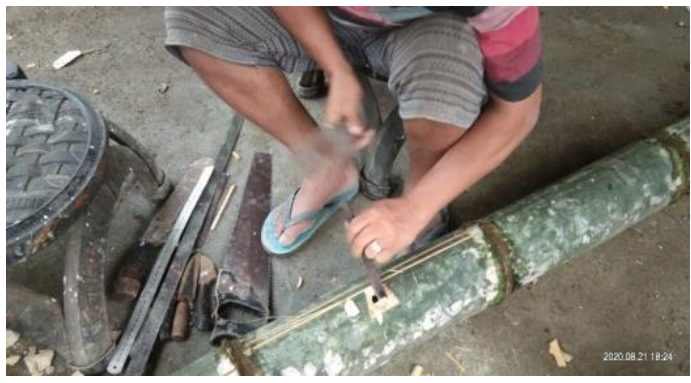

Gambar 6. Proses membuat lubang suara

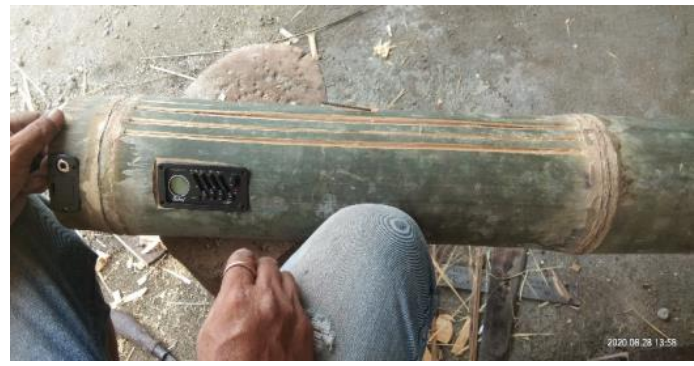

Gambar 7. Proses memasang equalizer

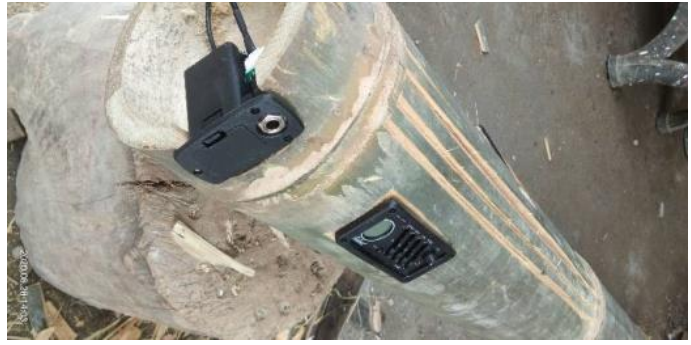

Gambar 8. Equalizer Keteng-keteng

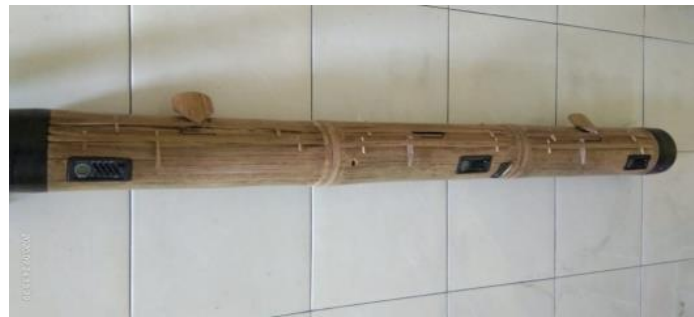

Gambar 9. Keteng-keteng elektrik Telu Ngawan

Teknik Permainan Keteng-keteng Elektrik Telu Ngawan

Memainkan Keteng-Keteng Elektrik Telu Ngawan haruslah memahami karakter suara dari keteng-keteng tersebut. Hal ini sudah dijelaskan pada paparan sebelumnya bahwa keteng-keteng merupakan gabungan tiga buah instrumen yang dijadikan kedalam satu bilah bambu. Ketiga instrumen tersebut adalah gendang anak dan indung, penganak dan gung. Ketiga instrumen tersebut mempunyai karakter yang berbeda, namun untuk menghasilkan bunyi gung dan penganak cukup hanya dengan pukulan biasa. Untuk menghasilkan bunyi gendang mempunyai 2 teknik yang berbeda sesuai dengan bunyi yang dihasilkan, oleh sebab itu gendang harus menghasillkan karakter tang dan cek. Bunyi tang dihasilkan dengan cara dengan sedikit diayun, sedangkan untuk menghasilkan cek dipukul sekaligus ditekan. Berikut gambar untuk teknik tang dan cek.

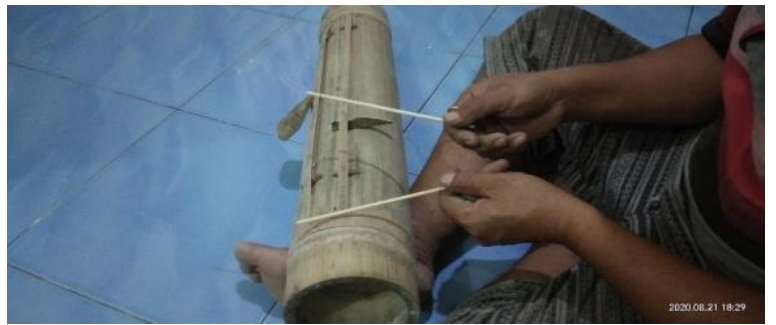

Gambar 10. Teknik Tang

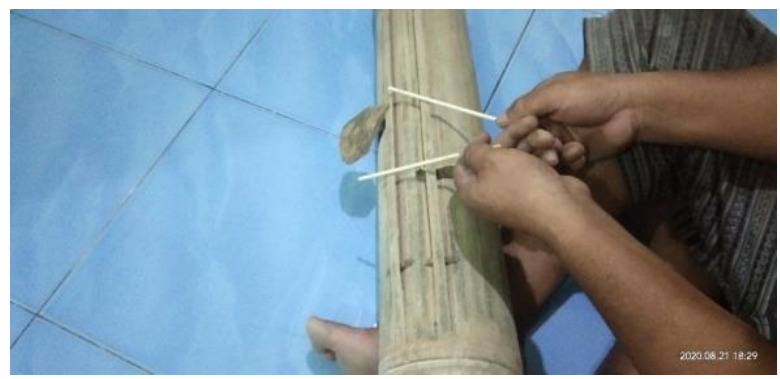

Gambar 11. Teknik Cek

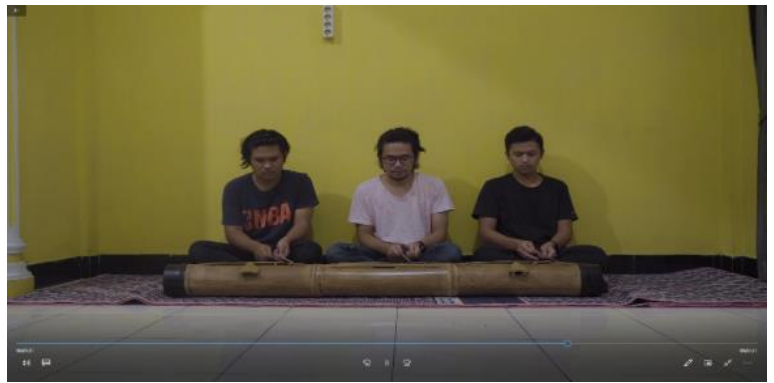

Gambar 12. Permainan Keteng-keteng Elektrik Telu Ngawan

\section{Komposisi Musik dengan Menggunakan Keteng-Keteng Elektrik Telu Ngawan}

Komposisi Keteng-keteng elektrik telu ngawan adalah idiom dari ritem tradisi Karo yaitu ritem odak-odak dan ritem patam-patam. 
Kedua ritem ini menjadi dasar dalam penciptaan komposisi keteng-keteng tiga ruas.

Adapun metode yang peneliti gunakan adalah metode diskomposisi dimana ritem yang sudah ada yaitu ritem odak-odak dan ritem patam-patam dihancurkan terlebih dahulu kemudia disusun Kembali untuk dijadikan komposisi. Metode ini digunakan agar kesan ke karo-an dari ritem tradisi karo tidak hilang walau dijadikan komposisi baru.

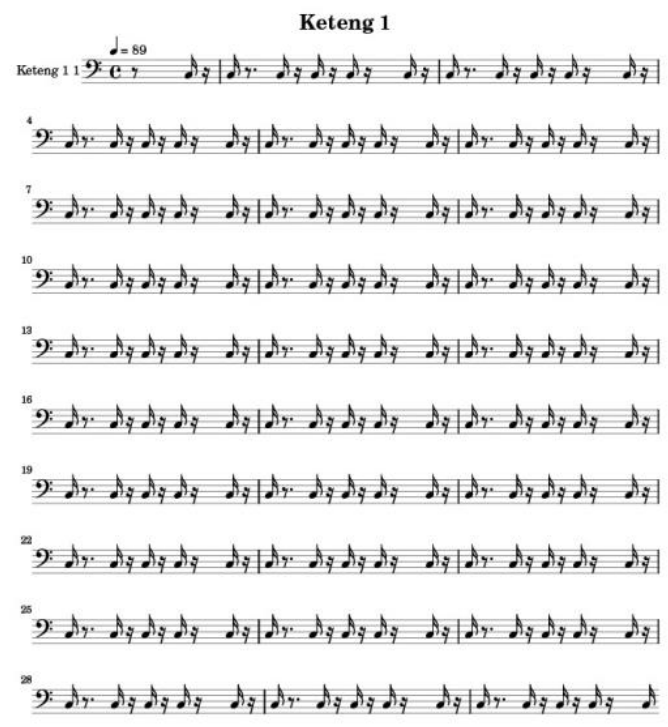

Gambar 13. Komposisi musik keteng 1

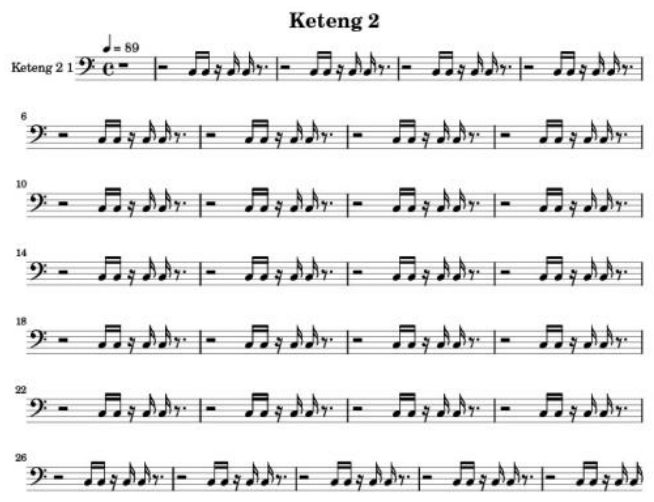

Gambar 14. Komposisi musik keteng 2

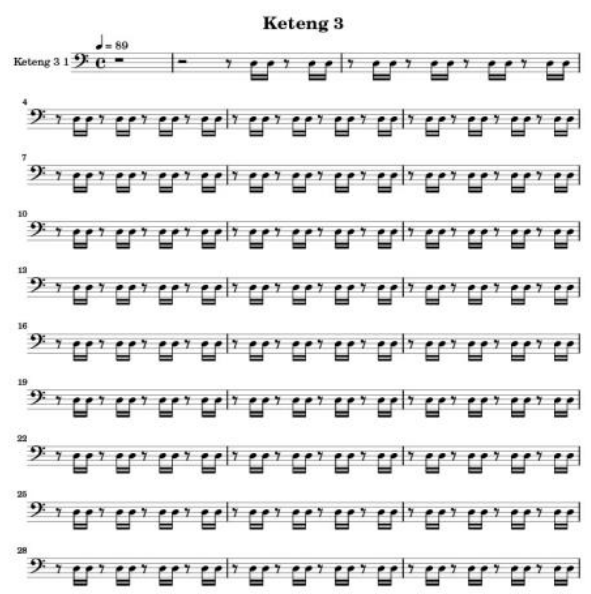

Gambar 15. Komposisi musik keteng 3

\section{PENUTUP}

Penciptaan keteng-keteng elektrik telu ngawan dilakukan dengan cara meng-explore warna bunyi (timbre) dalam satu bambu yang memiliki tiga ruas. Ketigaruas bambu dituning berbeda melalui senar dan lubang resonansi serta dilah atau lidah penggetar suara. Ketiga karakter yaitu high, midle, low akan ditentukan dari tebal tipisnya senar dan besar kecilnya lubang resonansi serta ukuran dilah-nya.

Teknik memainkan Keteng-Keteng Elektrik Telu Ngawan haruslah memahami karakter suara dari keteng-keteng tersebut, yaitu gendang anak dan indung, penganak dan gung. Untuk menghasilkan bunyi gung dan penganak cukup hanya dengan pukulan biasa, sedangkan untuk menghasilkan bunyi gendang mempunyai 2 teknik yang berbeda sesuai dengan bunyi yang dihasilkan. Gendang harus menghasillkan karakter tang dan cek. Bunyi tang dihasilkan dengan cara dengan sedikitdi ayun, sedangkan untuk menghasilkan cek dipukul sekaligus ditekan.

Komposisi Keteng-keteng elektrik telu ngawan adalah idiom dari ritem tradisi Karo yaitu ritem odak-odak dan ritem patam-patam. Kedua ritem ini menjadi dasar dalam penciptaan komposisi keteng-keteng tiga ruas. Adapun metode yang peneliti gunakan adalah metode diskomposisi dimana ritem yang sudah ada yaitu ritem odak-odak dan ritem patampatam dihancurkan terlebih dahulu kemudia disusun kembali untuk dijadikan komposisi. Metode ini digunakan agar kesan ke karo-an dari ritem tradisi karo tidak hilang walau dijadikan komposisi baru.

\section{DAFTAR PUSTAKA}

Ediwar Ediwar . dkk. 2019. Kajian Organologi Pembuatan Alat Musik Tradisi Saluang 
Darek Berbasis Teknologi Tradisional. Jurnal Seni Budaya Panggung Vol.2 No. 2.

Purba, Mauli, 2007, Musik Tradisional Masyarakat Sumatera Utara: Harapan Peluang, Dan Tantangan. Medan: Universitas Sumatera Utara.

Soewito, 1996. Mengenal Alat-alat Musik Tradisional. Yogyakarta : Sinar Harapan.

Syafig, Muhammad, 2003. Ensiklopedia Musik Klasik. Yogyakarta: Adicita Karya Nusa.

Tarigan, Perikuten. 2004. Pluralitas Musik Etnik. Pusat Dokumentasi dan Pengkajian Kebudayaan Batak. Universitas HKBP Nommensen.

Sagala, Mastri Dihita. 2017. Pola Irama Keteng-Keteng Dalam Pertunjukan Gendang Telu Sendalanen Masyarakat Karo, S1 thesis, Universitas Pendidikan Indonesia.

Hermansyah, L. (2020). Instrumen Snare Drum Produksi Al Custom Drum Di Kediri Jawa Timur Dalam Tinjauan Organologi dan Menejerial Pemasaran. Virtuoso: Jurnal Pengkajian dan Penciptaan Musik, 3(1), 12-22.

doi:http://dx.doi.org/10.26740/vt.v3n1.p1 2-22 